\section{Improving integration of clinical clerkship didactic curriculum}

\author{
Lindsay Mazotti, ${ }^{1,2}$ Heidi E. Kirsch, ${ }^{3,4}$ \\ Bridget O'Brien²
}

1Kaiser Permanente Oakland, Department of Hospital Medicine

2Department of Medicine, University

of California San Francisco

3Department of Neurology, University

of California, San Francisco

4Department of Radiology and

Biomedical Imaging, University

of California, San Francisco, USA

\section{Abstract}

Curricular integration is a primary focus of many efforts to improve clinical education, but the practical realities of connecting content across discipline-based learning experience is a formidable challenge. This paper describes the construction of a third-year clinical clerkship curriculum featuring integrated didactics, purposeful sequencing, linkage to clinical context and introduction of competency-based learning activities. We describe the organization of our curriculum, the methods by which we integrated our didactic curriculum, and the results of curricular evaluations. Over two years, we improved integration and reduced fragmented learning experiences in a longitudinal integrated clerkship. Individual lectures were highly rated with a mean overall score of $4.29(\mathrm{SD}=0.78)(1=$ poor, $5=$ excellent $)(\mathrm{N}=23)$. Integrated didactic sessions and competencybased learning activities, including a quality improvement curriculum and reflection sessions, were also highly rated. Purposeful integration of clinical content, sequencing of didactics across the academic year, linking didactic content to a clinical context and creating new competency-based learning activities were highly rated and feasible ways to combine didactics across disciplines in the core clerkship year. Similar integrated curricula may be used with students in longitudinal integrated clerkships or in a traditional third-year clerkship model.

\section{Introduction}

For more than two decades there have been calls to improve integration in medical school curricula. ${ }^{1,2}$ Integration involves organizing curricular content in ways that connect topics across disciplines, courses and/or departments; the goal is to facilitate development of knowledge structures that support effective clinical reasoning.1,3-6 Though many pre-clinical curricula are examples of multi-disciplinary or interdisciplinary integration, $, 7,8$ the curricula of the core clinical clerkships remain mostly isolated, with clerkships taking place in approximately eight week blocks and clerkship directors largely unaware of the content of the other clerkships. ${ }^{2,9,10}$ The curriculum of the clerkships is fragmented, with students rotating through clerkships in no particular order, at multiple sites, with many different teachers. This fragmentation may add to the tremendous variability in clinical experiences, knowledge, and skill development among students. ${ }^{11}$ Similarly, clinical skills are introduced in random order, depending upon the order of assigned clerkships. Furthermore, though the competencies set forth by the Accreditation Council for Graduate Medical Education (ACGME) provide opportunity to improve integration in the core clinical year by emphasizing qualities and skills necessary across all clerkships, ${ }^{12-14}$ there is little consensus on how to teach these competencies in an interdisciplinary manner.

\section{Innovation}

In 2007, the University of California San Francisco (UCSF) implemented a longitudinal integrated clerkship (LIC) called PISCES (Parnassus Integrated Student Clinical Experiences). In PISCES, students complete concurrent ambulatory preceptorships in each core discipline over the course of one year and have continuity with a panel of patients, preceptors and one hospital system.

PISCES School is a yearlong, half-day curriculum designed to provide the didactic clerkship learning within our LIC. Clerkship leaders reviewed literature and interviewed colleagues at schools with innovative clerkship models ${ }^{15-17}$ and based our curriculum upon three guiding principles (Table 1). Two faculty members compiled all topics taught in block clerkships, all core clerkship learning objectives, and the 6 ACGME core competencies into one database. Departmental liaisons estimated the number of didactic hours that they would need to teach topics during PISCES School. Iterations of the didactic schedule were presented to clerkship leaders until consensus was reached.

\section{Integration of didactics}

Content from two disciplines with overlap were scheduled as one session, meeting objectives from both departments; ideally, these sessions were team-taught to promote interdisciplinary integration. We paired topics in newways (e.g. diabetes and behavioral change, or breast cancer and cancer survivorship), to
Correspondence: Lindsay Mazotti, Department of Hospital Medicine, Kaiser Permanente Oakland. Assistant Clinical Professor of Medicine, University of California San Francisco 280 West MacArthur Blvd., Oakland, CA, 94610 USA.

E-mail: lindsay.a.mazotti@kp.org

Key words: clinical, integration, medical, student

Acknowledgements: the authors wish to thank the members of the PISCES Development group, particularly Ann Poncelet, Patty Robertson, Tracey Jones, Karen Hauer, Lowell Tong, and Cindy Lai. We also wish to thank Patricia 0'Sullivan, Arianne Teherani and members of the UCSF ESCape Group for their review and assistance with this manuscript.

Received for publication: 18 August 2010.

Revision received: 22 November 2010.

Accepted for publication: 23 November 2010.

This work is licensed under a Creative Commons Attribution 3.0 License (by-nc 3.0).

(C) Copyright L. Mazotti et al., 2011

Licensee PAGEPress, Italy

Medical Education Development 2011; 1:e1

doi:10.4081/med.2011.e1

move towards complementary or multidisciplinary programs. Six topics were selected to be two- to four-hour Integrated Sessions, created and co-taught by faculty members from more than one discipline (Table 2), to present a multidisciplinary approach to the workup or management of a complex of symptoms.

Table 1. Core guiding principles for a longitudinal integrated clerkship curriculum

To meet the major knowledge-based and skillbased objectives outlined by the seven individual core clerkships.

To create and provide integrated, case-based small group tutorials deliberately sequenced to meet students emerging abilities and learning needs.

To introduce and evaluate learning activities for al 6 ACGME core competencies across all core clerkships.

Table 2. Integrated Sessions in PISCES School.

\begin{tabular}{ll} 
Session title & Clerkships involved \\
$\begin{array}{l}\text { GI Bleeding } \\
\text { Altered mental status }\end{array}$ & Medicine, surgery \\
\hline Substance abuse & $\begin{array}{l}\text { Family \& community } \\
\text { medicine, psychiatry }\end{array}$ \\
Mood disorders & $\begin{array}{l}\text { Family \& community } \\
\text { medicine, psychiatry }\end{array}$ \\
\hline $\begin{array}{l}\text { Anemia \& } \\
\text { thrombocytopenia } \\
\text { Intimate partner } \\
\text { violence }\end{array}$ & Medicine, pediatrics \\
\hline
\end{tabular}




\section{Integration though sequencing}

Examples of sequencing have been seen at other institutions, ${ }^{16-18}$ where the clinical year begins by focusing on presenting symptoms and syndromes, then moves into diseases and disease management. The rationale is that many common presentations (e.g. abdominal pain) apply to multiple clerkship disciplines (e.g. medicine, pediatrics, obstetrics/gynecology) and thus are useful to learn early in the year. More complex disease management is then moved later into the year, when students have a higher level of clinical experience and reasoning skills, and are ready to tackle the plan in addition to the assessment.

Similar to the Cambridge Integrated Clerkship (CIC) tutorials, ${ }^{17}$ our curriculum sequenced didactic sessions and reduced redundancy, both by combining related topics from multiple specialties into one session and by grouping sessions thematically. Sample afternoons of PISCES School and the objectives corresponding to each session are shown in Table 3. We also organized existing skill sessions - sessions that allowed hands-on practice with skills and procedures - in a developmentally appropriate fashion, for example placing EKG reading and surgical anatomy sessions at the beginning of the year-long curriculum, both skills necessary for early clinical reasoning and patient assessment. We created additional sessions, including sessions on radiology, oral presentations, casting, and anesthesia simulation (including cardio-pulmonary resuscitation and advanced cardiac life support instruction).

\section{Integration of clinical context}

Incorporating material from the real world of clinical care can provide the context necessary for transdisciplinary integration. ${ }^{6}$ Most PISCES School sessions included one hour of Student Report, a student-driven learning session where each student outlined a patient's presentation and course with facilitation by a faculty member, similar to a model of teaching in the CIC tutorials. ${ }^{17}$ This integration of clinical context allows for situated learning linked to meaningful practice situations. ${ }^{19}$

\section{Integration of competency-based learning activities}

Activities that meet the ACGME competencies, such as those focusing on communication or practice-based improvement, often emphasize general knowledge and necessary skills and attitudes. Such activities tend to transcend discipline-specific boundaries and allow for integration across clerkships. Medical Knowledge was addressed by didactic lectures and preceptorship experiences and assessed by examinations. Similarly, Patient
Care was addressed by clinical experiences and assessed by the Clinical Performance Examination and the United States Medical Licensing Examination, Step 2. Systems-based Learning was addressed by introducing a quality improvement (QI) curriculum, including a year-long, team-based QI project; a module on care transitions and hospital administrative sessions; and opportunities for students to interview hospital leaders on topics of health policy, information technology, and patientcentered care. Practice-Based Learning and Improvement was addressed by student selfevaluation exercises including bimonthly reflection sessions, journal exercises designed to prompt challenging or rewarding patient interactions, stress rounds with the Student Wellbeing Office, chart review sessions designed for students to examine their own

Table 3. Sample of two consecutive PISCES school afternoons.

\begin{tabular}{|c|c|c|c|c|c|}
\hline Date & Time & $\begin{array}{l}\text { Lecture } \\
\text { title }\end{array}$ & $\begin{array}{l}\text { Clerkship } \\
\text { responsible }\end{array}$ & \# of Hours & Theme \\
\hline Day 1 & $\begin{array}{l}1-3 \mathrm{pm} \\
3-5 \mathrm{pm}\end{array}$ & $\begin{array}{l}\text { Approach to } \\
\text { abdominal pain } \\
\text { Pediatric diarrhea, } \\
\text { abdominal pain } \\
\text { and dehydration }\end{array}$ & $\begin{array}{l}\text { Surgery } \\
\text { Pediatrics }\end{array}$ & $\begin{array}{l}2 \\
2\end{array}$ & Tummy trouble \\
\hline Day 2 & $\begin{array}{l}1-2 \mathrm{pm} \\
2-4 \mathrm{pm} \\
4-5 \mathrm{pm}\end{array}$ & $\begin{array}{l}\text { EKG Reading I } \\
\text { Approach to chest pain } \\
\text { Student report* cardiovascular }\end{array}$ & $\begin{array}{l}\text { Medicine } \\
\text { Medicine } \\
\text { Medicine }\end{array}$ & $\begin{array}{l}1 \\
2 \\
1\end{array}$ & Cardiac \\
\hline
\end{tabular}

* Students were asked to choose a patient topic relevant to the topic discussed that day in PISCES School.

Table 4. Activities of PISCES School mapped to ACGME core competencies.

\begin{tabular}{|c|c|c|c|}
\hline $\begin{array}{l}\text { PISCES School } \\
\text { activity }\end{array}$ & $\begin{array}{l}\text { ACGME } \\
\text { competency }\end{array}$ & $\begin{array}{l}\text { Exist as part } \\
\text { of at least One } \\
\text { block clerkship } \\
\text { (O) or All (A) } \\
\text { Clerkships } \\
\text { at UCSF }\end{array}$ & $\begin{array}{l}\text { New Session(s) } \\
\text { created for } \\
\text { PISCES School }\end{array}$ \\
\hline Didactic lectures & MK, PC & A & $\bullet$ \\
\hline Integrated cases & MK, PC & 0 & $\bullet$ \\
\hline Student report sessions & MK, PC & 0 & $\bullet$ \\
\hline Skills sessions & MK, PC & 0 & $\bullet$ \\
\hline Chart review sessions & PBLI, IPC, P & & $\bullet$ \\
\hline Peer-to-Peer feedback & PBLI, IPC, P & & $\bullet$ \\
\hline Video review sessions & IPC, P & 0 & $\bullet$ \\
\hline End-of-life curriculum & PC, Prof & 0 & - \\
\hline Stress rounds & Prof & 0 & $\bullet$ \\
\hline Quality improvement curriculum & SBP, IPC, P & & $\bullet$ \\
\hline Transitional care curriculum & SBP & 0 & $\bullet$ \\
\hline Hospital administrative sessions & SBP & & $\bullet$ \\
\hline
\end{tabular}

MK, medical knowledge, PC, patient care, PBLI, practice-based learning and improvement, IPC, interpersonal \& communication skills; P, professionalism; SBP, systems based practice

Table 5. Ratings of All PISCES School Lectures 2007-2009 ( $\mathrm{N}=23$ ).

\begin{tabular}{lcc} 
& Mean & Standard deviation \\
Quality of speaker and presentation & 4.34 & 0.76 \\
Success of educational objectives & 4.25 & 0.81 \\
\hline Relevance of topic to your education & 4.48 & 0.78 \\
Conference overall & 4.29 & 0.78 \\
\hline
\end{tabular}


veys completed at the end of each didactic session, which allowed us to compare PISCES School sessions to other non-PISCES sessions. Students are asked to rate individual didactic sessions on the quality of the speaker and presentation, the success of achieving educational objectives, the relevance of topic to education, and the session overall, using a scale of $1=$ low to 5 =high. Clerkship formal teaching (i.e. didactics and seminars) was evaluated using an institutional end-of-clerkship evaluation asking students, "On a scale of 1 (low) to 5 (high), rate your satisfaction with the quality of formal teaching," allowing us to also compare ratings. Four focus groups of the PISCES students included topics on PISCES School overall, on integration of topics, on developmental organization of topics, and on the skill, reflection, practice-based learning and feedback sessions.

The data reported in this paper are from the first two years of PISCES, 2007-2009. PISCES students $(\mathrm{N}=23)$ rated the overall quality of formal teaching 4.41 ( $\mathrm{SD}=0.49$ ), which is significantly higher than rating of formal teaching by block clerkship students $(\mathrm{N}=206) 4.11$ $(\mathrm{SD}=.41) \quad(\mathrm{P}<0.001)$. Overall, the individual PISCES School sessions were highly rated, with mean scores all between very good (4) and excellent (5) (Table 5). The mean scores for the six Integrated Cases were 4.78 (SD 0.21 ). Student Report sessions received a score of 5 from all students and was the highest-rated aspect of PISCES School. Skills sessions received a mean score of 4.61 $(\mathrm{SD}=0.33)$; the highest rated sessions were EKG reading, anesthesia skills sessions and heart sound rounds. The mean score for the QI curriculum was $4.43(\mathrm{SD}=0.59)$, for stress rounds was $4.35(\mathrm{SD}=0.48)$, and for reflection sessions was $4.66(\mathrm{SD}=0.35)$. The peer feedback and chart review exercises were part of a larger PISCES Program assessment effort; results will be reported in the future.

Focus groups over two years with all 23 LIC students revealed that one of the most valuable aspects of PISCES School was working with a group of peers over the year. Case-based learning was identified as the most helpful style of session and students preferred chalk talks over slide show talks. Sessions requiring preparation beforehand were helpful, as they required all students to come prepared to discuss; students preferred optional objectives and reading to assigned homework. Students appreciated diversity in the lecturers, enjoying different teachers from each discipline rather than having one teacher for all topics from one discipline Integrated Cases, Student Report and hands-on workshops and skill sessions with models or real patients were also praised in the focus groups.

Students in PISCES performed comparably to students in traditional clerkships on the dis- cipline-specific end of clerkship examinations. There were no differences in the number of Honors grades awarded to PISCES versus traditional students.

\section{Conclusions}

As we focus on reducing fragmentation in the clinical clerkship experience and progress toward a competency-based curriculum, linking the content of clinical clerkships becomes increasingly necessary.

Based on results of our curricular evaluation, we recommend the following best practices for creation of such curricula. Case-based and patient-centered learning should be used in didactic sessions when possible. Though integrated cases are highly rated by students, their development is time-intensive and for practical reasons may need to be done over time rather than at the inception of the curriculum. Incorporating pre-existing integrated sessions, allowing for on-the-fly co-teaching by faculty from different disciplines, and inviting current and former LIC students to create integrated cases has allowed us to increase the number of integrated sessions. Maintaining a constant, small peer group for didactic sessions is another key feature of the success of our curriculum, though having smaller groups necessitated more faculty facilitators. Teaching models such as team-based learning could work well for clerkships limited by faculty time. ${ }^{20}$

In summary, this curriculum reduces the fragmented learning experiences of the clinical year by allowing for integration of clinical topics and provides a strong framework based on the ACGME core competencies. Such a curriculum can be adapted to traditional clerkships or an LIC.

\section{References}

1. Harden RM, Sowden S, Dunn WR. Educational strategies in curriculum development: The SPICES model. Med Educ 1984;18:284-97.

2. Cooke M, Irby DM, Sullivan W, Ludmerer KM. American medical education 100 years after the Flexner report. N Eng J Med 2006;355:1339-44.

3. Hauer KE, 0'Brien B, Poncelet AN. Longitudinal integrated clerkship education: better for learners and patients. Point. Acad Med 2009;84:821.

4. Muller JH, Jain S, Loeser H, Irby DM. Lessons learned about integrating a medical school curriculum: perceptions of students, faculty and curriculum leaders. Med
Educ 2008;42:778-85.

5. Bordage G. Elaborated knowledge: a key to successful diagnostic thinking. Acad Med 1994;69:883-5.

6. Harden RM. The integration ladder: a tool for curriculum planning and evaluation. Med Educ 2000;34:551-7.

7. Irby DM, Wilkerson L. Educational innovations in academic medicine and environmental trends. J Gen Intern Med 2003;18: 370-6.

8. Wilkerson L, Stevens CM, Krasne S. No content without context: integrating basic, clinical, and social sciences in a pre-clerkship curriculum. Med Teach 2009;31:81221.

9. Hirsh DA, Ogur B, Thibault GE, Cox M. "Continuity" as an organizing principle for clinical education reform. $\mathrm{N}$ Eng $\mathrm{J}$ Med 2007; 356:858-66.

10. Liaison Committee for Medical Education. http://www.lcme.org/functions2008jun.pdf. Accessed November 19, 2010.

11. Armstrong EG, Mackey M, Spear SJ. Medical education as a process management problem. Acad Med 2004;79:721-8.

12. West CP, McDonald FS. Evaluation of a longitudinal medical school evidencebased medicine curriculum: A pilot study. J Gen Intern Med 2008; 23:1057-9.

13. Accreditation Council for Graduate Medical Education. http://www.acgme.org/ outcome/comp/compMin.asp, Accessed November 19, 2010.

14. Clerkship Directors in Internal Medicine. http://im.org/CDIM. Accessed November 19, 2010.

15. BellSK, Krupat E, Fazio SB, et al. Longitudinal pedagogy: a successful response to the fragmentation of the thirdyear medical student clerkship experience. Acad Med 2008;83:47-75.

16. Ogur B, Hirsh D, Krupat E, Bor D. The Harvard Medical School-Cambridge integrated clerkship: an innovative model of clinical education. Acad Med 2007;82:397404.

17. Cohen, P. Training for expertise: The Harvard Medical School Cambridge Integrated Clerkship tutorial. Clinical Teacher 2009;6:28-33.

18. Mandin H, Harasym P, Eagle C, Watanabe, M. Developing a "clinical presentation" curriculum at the University of Calgary. Acad Med 1995;70:186-93.

19. Brown JS, Collins A, Duguid P. Situated cognition and the culture of learning. Educ Res 1989;18:32-42.

20. Michaelson L, Sweet M, Parmelee D. Team-based learning: Small-group learning's next big step. San Francisco: Wiley Periodicals. 2008. 